\title{
14th European Conference for Clinical Hemorheology and Microcirculation, Dresden, Germany, June 27-30, 2007
}

The 14th European Conference for Clinical Hemorheology and Microcirculation has been held in Dresden, Germany, June 27-30, 2007, organized by the European Society for Clinical Hemorheology and Microcirculation - a federation of National Societies with a local organizer - The German Society for Clinical Hemorheology and Microcirculation. Different pharmaceutical and other companies have supported the congress and have presented their diagnostic and therapeutic products.

Table 1 summarizes the previous meetings with the years, locations and names of the presidents and Fåhraeus medal recipients.

About 122 active participants from different branches of medicine, biology, pharmacology, physics, mechanics and chemistry from Austria, Bulgaria, Canada, Czech Republic, France, Germany, Great Britain, Greece, Hungary, Italy, Iran, Netherlands, Poland, Portugal, Romania, Russia, South Korea, Singapore, Spain, Sweden, Switzerland, Turkey, Ukraine and USA have presented 102 lectures and/or posters during the 14th European Conference for Clinical Hemorheology and Microcirculation in Dresden.

Table 1

Previous meetings with the years, locations and the names of presidents and Fåhraeus medal recipients

\begin{tabular}{lllll}
\hline & Year & Site & President & Fåhraeus awardee \\
\hline 1st & 1979 & Nancy & J. F. Stoltz & - \\
2nd & 1981 & London & J. Dormandy & Shu Chien \\
3rd & 1983 & Baden-Baden & H. Schmid-Schonbein & John Dormandy \\
4th & 1985 & Siena & T. Di Perri & Holger Schmid-Schonbein \\
5 th & 1987 & Bordeaux & M. Boisseau & Jean Francois Stoltz \\
6th & 1989 & Frankfurt & A. Ehrly & Tullio Di Perri \\
7th & 1991 & Southampton & S. Roath & John Stuart \\
8th & 1993 & Vienna & E. Ernst & Herbert Meiselman \\
9 th & 1995 & Siena & T. Di Perri & Albrecht Ehrly \\
10th & 1997 & Lisbona & J. Martins e Silva & Siegfried Witte \\
11 th & 2000 & Rouen & G. Potron & Gustav Born \\
12th & 2003 & Sofia & N. Antonova & Sandro Forconi \\
13th & 2005 & Siena & S. Forconi & M.R. Boisseau \\
14th & 2007 & Dresden & F. Jung & M. Rampling \\
\hline
\end{tabular}


The plenary lectures have been delivered by M. Jünger (University Greifswald, Germany) about rheological and microcirculatory disorders in patients with venous insufficiency, by N. Chung (Yonsei University, South Korea) about ultrasound media contrast enhanced detection of coronary microangiopathy, by J.-W. Park (Hoyerswerda Hospital, Germany) about magnetocardiography - a new tool, for the detection of myocardial ischemias, and by A. Vaya (University Valencia, Spain) about hemorheological parameters as independent risk factors for deep vein thrombosis. The Fåhraeus medal has been awarded to Professor Mike Rampling from London, Great Britain - an outstanding leading scientist in the field of Clinical Hemorheology. The special Fåhraeus Lecture: "The great Divide - from viscometer to vasculatire" illustrating the course of 30 years in studying blood flow properties, delivered by M. Rampling was the highlight of the meeting. The Bulgarian, Italian and the German Societies have been very active in the organization of symposia as well as the International Society. It is my true hope that this collaboration will last in the future. I want to thank Herb Meiselman and Oguz Baskurt of the ISCH for this help.

Organizing meetings of the Council and the Advisory board of the European Society and of the Editorial Board of the journal Clinical Hemorheology and Microcirculation have been held. After a wide discussion it has been decided that the next European Conference will be held in the Switzerland organized by Prof. W. Reinhart in 2009.

The organizers thank all the participants and the institutions with which cooperation the Conference could be realized.

December 2007

Friedrich Jung President of the Conference 